$\xi=-1$

\title{
Evaluation of the gap area between two sided friction stir welding of AA 2024-T351
}

\author{
Hassan H. Mahdi ${ }^{1}$, Moneer Hameed Tolephih ${ }^{2}$, Nasri S. M. Namer ${ }^{3 *}$ \\ ${ }^{1}$ Engineering Technical College - Baghdad, Middle Technical University - Iraq \\ ${ }^{2}$ University of Kerbela - Iraq \\ ${ }^{3}$ Engineering Technical College - Baghdad, Middle Technical University - Iraq \\ *Corresponding author E-mail: nasrinamer@mtu.edu.iq
}

\begin{abstract}
The joints fabricated by two sided friction stir welding has shown higher ultimate tensile strength as compared to the joints fabricated by single pass and this trend is common for all the tool profiles.

The joining of AA 2024-T351 aluminum plates with dimensions $200 \mathrm{~mm} \times 200 \mathrm{~mm} \times 5 \mathrm{~mm}$ (Length $\times$ width $\times$ thickness) was carried out by double pass friction stir welding (FSW) technique. Three friction stir welding tools with different pin height $(1,1.5 \mathrm{and} 2) \mathrm{mm}$ were used with different stirring rotation speeds and travel speed, (560, 710 and 900) RPM and (16, 20 and 25) $\mathrm{mm} / \mathrm{min}$ respectively.

The welded specimens were analyzed and evaluated using microstructure, macrostructure, tensile and hardness tests. The results indicated that the yield strength and tensile strength increases as the distance between the two passes (double pass) decrease, the rotational speed of 900 RPM and 560 RPM with travel speed of $16 \mathrm{~mm} / \mathrm{min}$ and $25 \mathrm{~mm} / \mathrm{min}$, respectively is considered to be the most efficient and the width of the gap of the joint line decrease as the distance between the two welding pass decreases.
\end{abstract}

Keywords: Aluminum Alloys; Friction Stir Welding; Double Pass Technique; Mechanical Properties; Welding Passes.

\section{Introduction}

Heat treatable 2xxx series aluminum alloys with high strength levels and favorable strength to weight ratios are one of the best candidate materials for meeting the challenges of structural applications in the aerospace industry. But the loss of strength in the components fabricated from these alloys using the conventional fusion welding techniques, poses a serious limitation in their utilization for these purposes [1]. Usually, most of the fabricated components and structures are of welded construction and the problems associated with the fusion welding of these aluminum alloys, like porosity, slag inclusion, solidification cracks, and distortion, deteriorate the weld quality and the resultant joint properties [2]. Friction stir welding (FSW) is a recent method of joining materals patented in 1991 by TWI, this process was developed from the classic friction welding methods and has the advantage of operating in solid state [3-5]. In conventional friction welding the plasticized material is constrained in two dimensions (vertical and horizontal), while in FSW the layer of plasticized material is constrained in three dimensions [3]. FSW assures the absence of porosity, distortion and residual stresses, which are typical defects of the fusion welding processes, and the possibility to operate in all positions without protective gas. The process uses a shouldered rotating tool with a profiled pin that penetrates the clamped parts to be joined; the tool then starts to move along the join line. The heat produced by friction softens the alloy and the pin stirs the material of the joint until the sheets are joined. The stirring of one material into the other is associated with a solid-state flow, i.e. with a very high deformation, and involves recrystallization of a portion of the joint (weld nugget). These extremely fine recrystallized grains are known to slide one over the other, leading to a super-plastic flow that accommodates the FSW process. FSW temperature decreases from the top to the bottom of the joint, a change that corresponds to a variation in recrystallized grain size [3], [6-8]. Many authors are studied the microstructure characterization for AA 2024 aluminum alloy. (Srivatsan et al., 2016) studied the effect of welding parameter on the microstructural development of a $3 \mathrm{~mm}$ thick plate of the AA 2024 aluminum alloy [4]. (Booth et al., 2003) analyzed the local microstructure and hardness of 13mm gauge AA 2024-T351 aluminum alloy friction stir welds [9]. (Von der Fakultät et al., 2008) studying the influence of energy input in friction stir welding on structure evolution and mechanical behavior of precipitation-hardening in aluminum alloys AA 2024-T351, AA 6013-T6 and Al-Mg-Si [10]. Few researchers studied the double side friction stir welding; such as (Barnes et al., 2008) which studied, residual strains and microstructure development in single and sequential double sided friction stir welds in RQT-701 steel [11]. (Sathari et al, 2014) proved and confirmed that the joint strength and percentage elongation of the welds of double sided joints are better than for single-pass joints [12]. (Hejazi and Mirsalehi, 2015) studied the double-sided friction stir welding of AA6061 sheet and compared with its conventional single-sided one [13]. FSW tools with different pin lengths $(50 \%-95 \%$ of the sheet thickness) were used to perform the double-sided welds. Macro- and micro-structures, strength, and hardness of the joints were investigated to determine the optimum pin penetration depth. The best results were obtained for a double-sided joint made with a pin length equal to $65 \%$ of the sheet thickness, which showed an increase of $41 \%$ in the ultimate tensile strength compared with the single-sided joint.

In this study the mechanical and microstructural characteristics of two sided (double side) friction stir welding of AA 2024-T351 aluminum alloy were analyzed with respect to different friction 
stir welding tools pin height, stirring rotation speeds and travel speed to evaluate the best gap distance between the two sided of friction stir welding which give good welded joint.

\section{Experimental procedure}

The material used in this study is $5 \mathrm{~mm}$ thick plate of AA 2024 T351 aluminum alloy, the chemical composition and mechanical properties of AA 2024-T351 are shown in Tables 1 and 2. Three friction stir welding tools were machined from high speed steel, with $18 \mathrm{~mm}$ shoulder diameter, $5 \mathrm{~mm}$ pin diameter for all tools and $1,1.5$ and $2 \mathrm{~mm}$ pin height. The FSW process was conducted on square aluminum alloy plates with the size $200 \mathrm{~mm}$ x $200 \mathrm{~mm}$. Three different rotational speeds were used for welding processes 560, 710 and 900 RPM with three different travel speeds 16, 20 and $25 \mathrm{~mm} / \mathrm{min}$.

Table 1: Chemical composition of aluminum alloy AA 2024-T351.

\begin{tabular}{llllllll}
\hline \multirow{2}{*}{ Material } & \multicolumn{6}{c}{ Element (\%) } \\
& $\mathrm{Si}$ & $\mathrm{Fe}$ & $\mathrm{Cu}$ & $\mathrm{Mn}$ & $\mathrm{Mg}$ & $\mathrm{Zn}$ & $\mathrm{Al}$ \\
\hline \multirow{2}{*}{ Nominal } & 0.5 & 0.5 & $3.8-$ & $0.3-$ & $1.2-$ & 0.25 & \multirow{2}{*}{ Bal. } \\
& $\max$ & $\max$ & 4.9 & 0.9 & 1.8 & $\max$ & Bal. \\
\hline
\end{tabular}

Table 2: Monotonic properties of aluminum Alloy AA 2024-T351.

\begin{tabular}{llll}
\hline $\begin{array}{l}\text { AA2024- } \\
\text { T351 }\end{array}$ & $\begin{array}{l}\text { Tensile strength } \\
(\mathrm{MPa})\end{array}$ & $\begin{array}{c}\text { Mechanical Properties } \\
\text { Yield strength } \\
(\mathrm{MPa})\end{array}$ & $\begin{array}{l}\text { Elongation } \\
(\%)\end{array}$ \\
\hline Nominal & 483 & 345 & $14-16$ \\
Measured & 560 & 460 & 14.2 \\
\hline
\end{tabular}

Each welding condition was used for three different double pass welding processes. The former was done with $1 \mathrm{~mm}$ pin height ( $3 \mathrm{~mm}$ distance between the two passes), the second was done with $1.5 \mathrm{~mm}$ pin height ( $2 \mathrm{~mm}$ distance between the two passes) and the last one was done with $2 \mathrm{~mm}$ pin height $(1 \mathrm{~mm}$ distance between two passes). Tensile tests were conducted on tensile testing machine with a constant cross-head speed of $1 \mathrm{~mm} / \mathrm{min}$ according to ASTM B557M after removing the welding zones and observing the distance between two welding passes as shown in Figure.1.

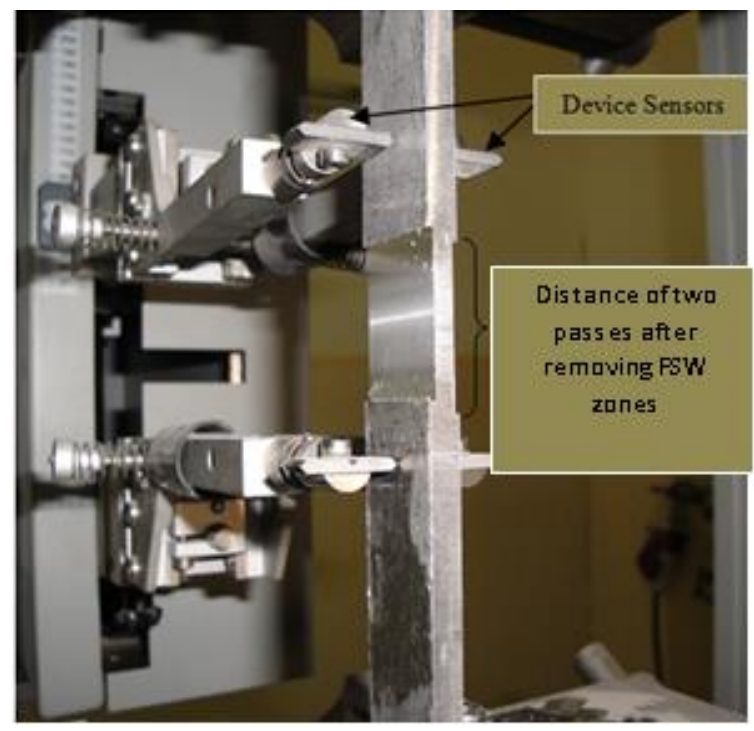

Fig. 1: Tensile specimen on tensile device after removing the FSW zones.

\section{Results and discussion}

Figure 2 shows the microstructure of the transverse surface across the welding zone. In FSW aluminum joints four zones are clearly shown: the Nugget Zone (NZ) is created by the penetrating tool pin and characterized by a recrystallized microstructure containing very fine grains, which are formed as a result of the severe plastic deformation and high temperatures (Figure 2-c) surrounded by the Thermomechanically Affected Zone (TMAZ) (Figure 2-b) is characterized by a highly deformed structure. A distinct boundary between the NZ and TMAZ is seen on the advancing side, unlike the unclear demarcation on the retreating side [1, 4-6]. Consequently, it can be said that, microstructural changes in TMAZ are driven by the combined influence of heat generated and deformation induced by the tool and the Heat Affected Zone (HAZ) on either side of the joint line. The difference in grain shape and dimensions between the weld nugget (Figure 2-c) and the parent (base) metal (Figure 2-a) is quite evident; the mean value of the grain size is $9 \mu \mathrm{m}$ in the weld nugget and $90 \mu \mathrm{m}$ in the parent alloy. Therefore, in the NZ, the grain size was approximately reduced by an order of a magnitude.
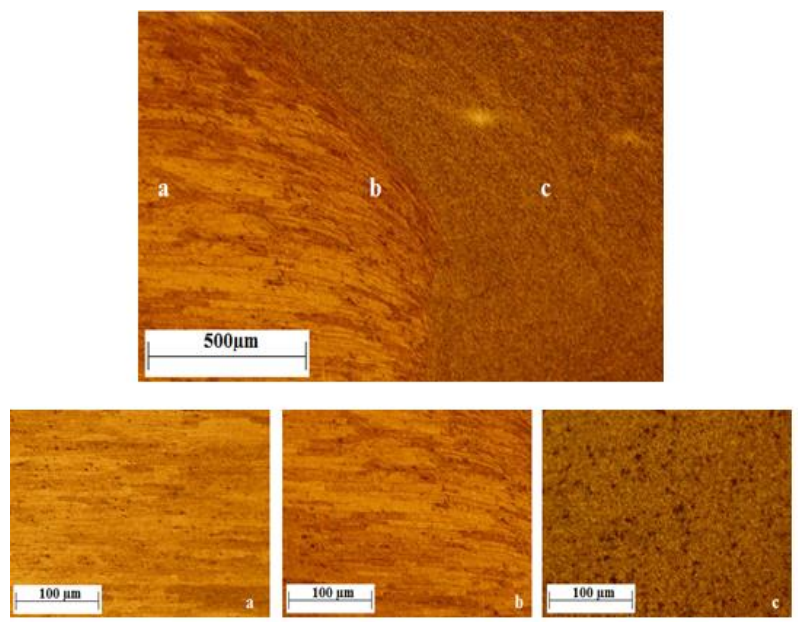

Fig. 2: Microstructure of the transverse surface across the welding zone (a) Base metal, (b) TMAZ and (c) NZ.

Figure 3 shows the macrostructure of FSW of welded specimens at one of the best rotation speed (900 RPM) and travel speed (16 $\mathrm{mm} / \mathrm{min}$ ). The width of the gap in the unwelded zone (joint line) between two friction stirs welding passes (double pass) was becoming very clear when the distance between passes increases.
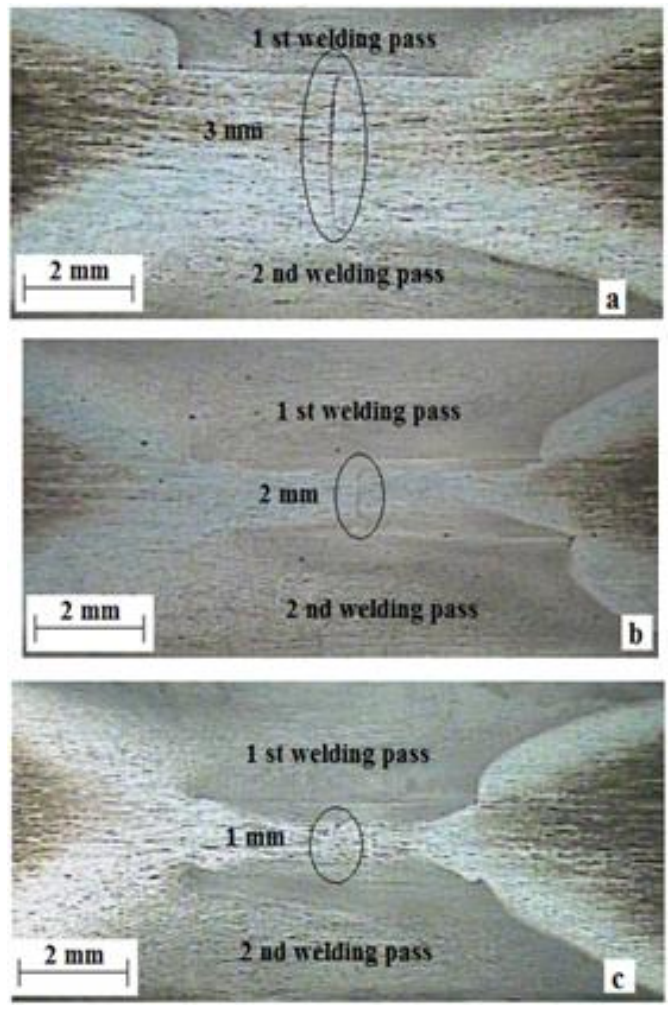

Fig. 3: Macrostructure of FSW of welded specimens at 900 RPM and 16 $\mathrm{mm} / \mathrm{Min}$. (a) $1 \mathrm{~mm}$, (b) $1.5 \mathrm{~mm}$ and (c) $2 \mathrm{~mm}$ pin height. 
Figure 4 shows the SEM used for determining the width of the gap in the unwelded zone. This figure showed the gap was about 13.5 $\mu \mathrm{m}$ for $2 \mathrm{~mm}$ distance between two welding passes, $8.2 \mu \mathrm{m}$ for 1.5 $\mathrm{mm}$ distance and $3.4 \mu \mathrm{m}$ for $1 \mathrm{~mm}$ distance.
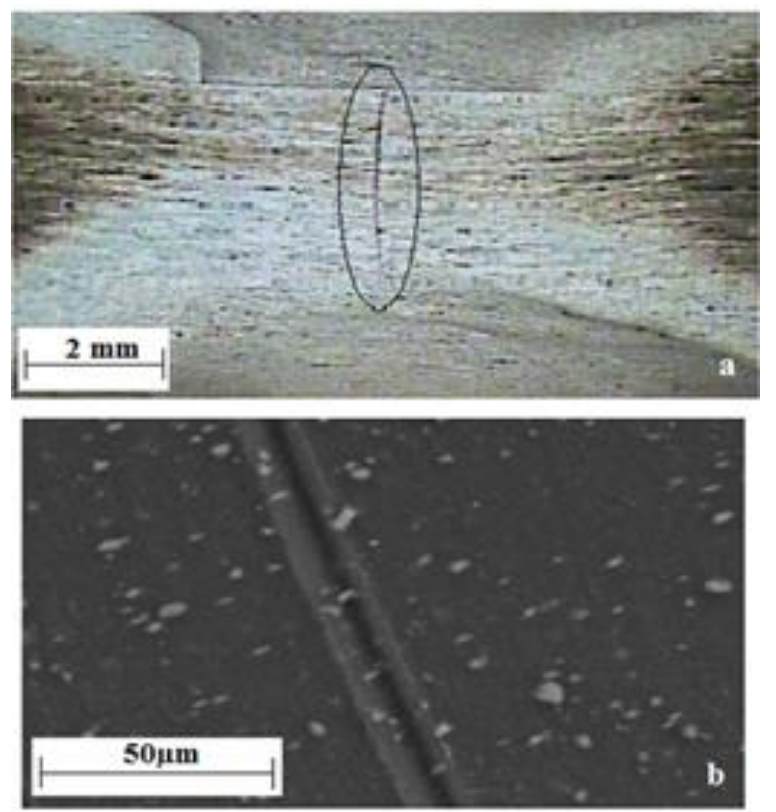

Fig. 4: Gap between Two Welding Passes Welded at 900 Rpm and 16 Mm/Min. (a) Macro-examination, and (b) SEM examination.

Microhardness tests (Hv0.05) were performed along the welded joint Figure 5, the hardness values are closely connected with the nature of the process experienced by the zones.

FSW creates a softened region around the weld center in precipitation hardened Al-alloys; the hardness profile in the particlehardened materials are mainly governed by the distribution of fine precipitates [3]. The lowest hardness value in Figure 5 is found in an area of high gain distortion indicated as zone "b" in Figure 2. A peak in hardness is observed in the central part of the NZ; then, MHV gradually decreases, reaches a minimum value in the HAZ, and gradually increases up to the value typical of the parent alloy.
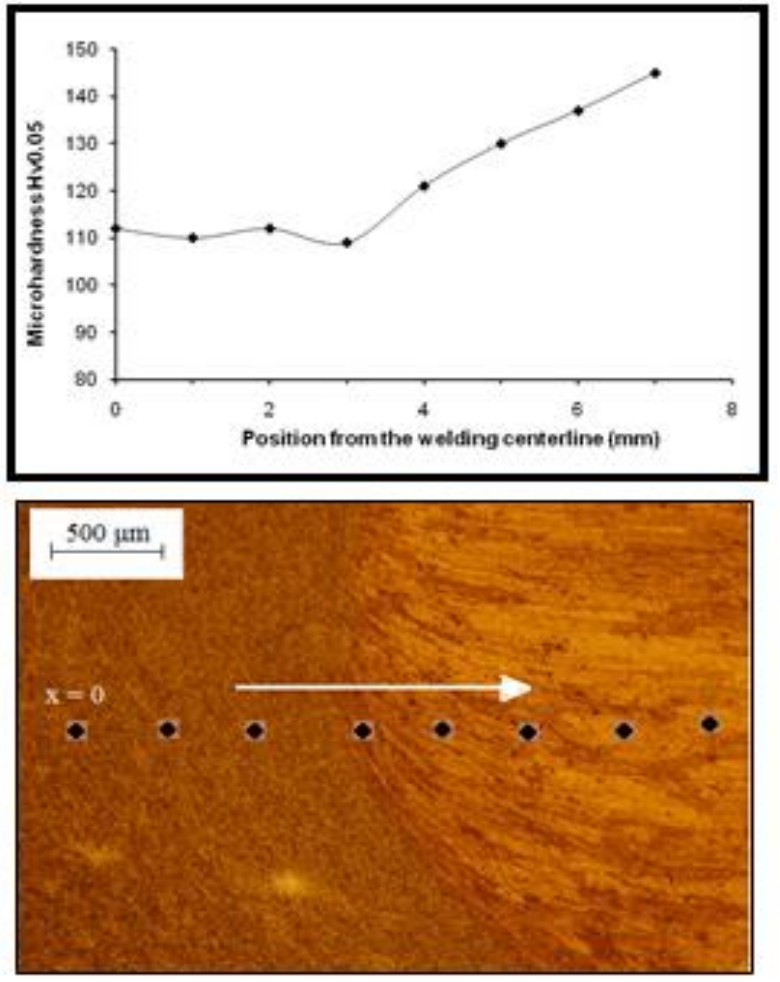

Fig. 5: Hardness Profile along the Welding Centerline for $900 \mathrm{Rpm}$ and 16 $\mathrm{Mm} /$ Min Welding Condition.
FSW creates a softened region around the weld center in precipitation hardened Al-alloys; the hardness profile in the particlehardened materials are mainly governed by the distribution of fine precipitates [3]. The lowest hardness value in Figure 5 is found in an area of high gain distortion indicated as zone "b" in Figure 2. A peak in hardness is observed in the central part of the NZ; then, MHV gradually decreases, reaches a minimum value in the HAZ, and gradually increases up to the value typical of the parent alloy. The yield and tensile strength of FSW variations with welding parameters are summarized in Table 3 . From this table can be concluded that the best strength was achieved when the stirring rotational speed was 900 RPM and 560 RPM with travel speed of $16 \mathrm{~mm} / \mathrm{min}$ and $25 \mathrm{~mm} / \mathrm{min}$ respectively, which means the high heat generation give good forging zone and also due increasing of welding pressure between the two passes of the double sided friction stir welding (at distance between two passes equal $1 \mathrm{~mm}$ ). The mechanical response of the welded sheets in terms of tensile strength and yielding is 55\% and 51\% respectively of that of the parent material.

The welded specimen strength and ductility were found to be lower than those of the base material that was characterized by the presence of precipitates of various sizes. For the alloy 2024, $\mathrm{Cu}$ is a principal alloying element, and the primary strengthening precipitates are the metastable $\hat{\theta}$ and $\theta$ phases [4, 9 and 10]. The study of the fracture location showed that in the as-received specimens the failure began from the transition zone of the cross-section (Figure (2b)), the result again is fully consistent with the available data which indicate that fractures do not occur in the weld nugget or in the joint centerline.

The result of percentage elongation presented in Table 3 shows good agreement with (Nofel et al., 2011) which concluded that the elongation percent decreases as welding pressure increase [14].

\section{Conclusion}

The double pass (two sided) friction stir welding process parameters were optimized with respect to mechanical and metallurgical properties of the welded AA 2024-T351 aluminum plates. This research concluded the following important points:

1) The yield and tensile strength increases as the distance between the two passes decrease.

2) The rotational speed of $900 \mathrm{RPM}$ and $560 \mathrm{RPM}$ with travel speed of $16 \mathrm{~mm} / \mathrm{min}$ and $25 \mathrm{~mm} / \mathrm{min}$ respectively is considered to be the most efficient.

3) The width of the gap of the joint line decrease as the distance between the two welding pass decreases.

4) Peak hardness observed in the NZ, reaching a minimum value at HAZ zone and gradually increases up to the typical value of the base metal.

\section{References}

[1] K.S. Arora, S. Pandey, M. Schaper and R. Kumar, "Microstructure evolution during friction stir welding of aluminuatam alloy AA2219", Journal of Materials Science \& Technology, Vol. 26, Issue 8, April 2010, pp.747-753. https://doi.org/10.1016/S10050302(10)60118-1.

[2] R.S. Mishra, Z.Y. Ma, "Friction stir welding and processing", Materials Science and Engineering: R-Reports, Vol. 50, Issue 1-2, August 2005, pp.1-78. https://doi.org/10.1016/i.mser.2005.07.001.

[3] M. Di. Paola, A. Falchera, M. Cabibbo, E. Evangelista, E. Meccia and S. Spigarelli, "Mechanical and microstructural characterization of an aluminum friction stir welded butt joint", Metallurgical Science and Technology, V1.0, No. 1, 2002, published in 2013,pp.1721.

[4] T.S. Srivatsan, Satish Vasudevan, "Influence of friction stir welding on microstructural development, mechanical response and fracture behavior of aluminum alloy 2024", ASM International, Processing and Fabrication of Advanced Materials XV (\#05201G), 2006, pp. 1-27.

[5] Bangcheng Yang, Junhui Yan, Michael A. Sutton, and Anthony P. Reynolds, "Banded microstructure in AA2024-T351 and AA2524- 

2003,

[6] John F. Bingert, Richard W. Fonda, "Transverse texture and microstructure gradients in friction-stir welded 2519 aluminum", Proceedings of the 4th International Symposium on Friction, Stir Welding, Park City, UT, May 14-16, 2003, Los Alamos national Laboratory, May 2003, pp. 112.

[7] R.W.Fonda and J.F. Bingert, "Microstructural evolution in the Heat-Affected Zone of a friction stir weld", Metallurgical and Materials Transactions A,Vol.35, Issue 5, May 2004, pp. 1487-1499. https://doi.org/10.1007/s11661-004-0257-7

[8] Emilie Bousquet, Angéline Poulon-Quintin, Monique Puiggali, Olivier Devos, Marie Touzet, "Relationship between microstructure, microhardness and corrosion sensitivity of an AA 2024-T3 friction stir welded joint", Corrosion Sience, Vol. 53, Issue 9, September 2011, , pp. 3026-3034. https://doi.org/10.1016/j.corsci.2011.05.049.

[9] D.P.P. Booth, M.J. Starink and I. Sinclair," Analysis of local microstructure and hardness of 13mm gauge 2024-T351 AA friction stir welds", Materials Science and Technology,Vol.23, Issue 3, 2007, Published in 2013, pp. 276-284.

[10] Von der Fakultt für Maschinenbau, "Influence of energy input in friction stir welding on structure evolution and mechanical behavior
T351 aluminum friction stir welds, Part I. Metallurgical studies", Materials Science and Engineering, Vol. A364, pp. 55-65.June

of precipitation- hardening in aluminum alloys (AA2024-T351, AA6013-T6 and Al-Mg-Si)", June 2008.

[11] S. J. Barnes, A. Steuwer, S. Mahawish, R. Johnson and P. J. Withers, "Residual strain and microstructure development in single and sequential double pass friction stir welds in RQT-701 steel", Material Science and Engineering: A, Vol. 492, Issue 1-2, September 2008, pp. 35-44. https://doi.org/10.1016/j.msea.2008.02.049.

[12] N.A.A. Sathari, L.H. Shah and A.R. Razali, "Investigation of single pass/double pass techniques on friction stir welding of aluminum", Journal of Mechanical Engineering and Sciences (JMES), Volume 7, pp. 1053-1061, December 2014 (C) University of Malaysia Pahang, Malaysia. https://doi.org/10.15282/jmes.7.2014.4.0102.

[13] Iman Hejazi and Seyyed Ehsan Mirsalehi, "Effect of pin penetration depth on double-sided friction stir welded joints of AA6061T913 alloy", Transaction of Nonferrous Metals Society of China, Volume 26, Issue 3, March 2016, pp. 676-683. https://doi.org/10.1016/S1003-6326(16)64158-4

[14] Nofel M.AL-Araji, Karrer M.Kadum, Akeel A. AL-Dayn, "Effect of friction stir welding pressure on the microstructure and mechanical properties of weld joints", International Journal of Scientific \& Engineering Research, Volume 2, Issue 12, December-2011, pp. 15 .

Table 3: Mechanical Properties Vary with Welding Parameters

\begin{tabular}{|c|c|c|c|c|c|c|c|c|c|}
\hline \multirow{3}{*}{$\begin{array}{l}\text { Travel speed }(\mathrm{mm} / \mathrm{min}) \\
\text { Distance between two passes }(\mathrm{mm})\end{array}$} & \multicolumn{9}{|c|}{ Stirring rotational speed $=560 \mathrm{RPM}$} \\
\hline & \multicolumn{3}{|c|}{16} & \multicolumn{3}{|c|}{20} & \multicolumn{3}{|c|}{25} \\
\hline & 1 & 2 & 3 & 1 & 2 & 3 & 1 & 2 & 3 \\
\hline Yield strength $\sigma_{\mathrm{y}}(\mathrm{MPa})$ & 213 & 213 & 152 & 232 & 178 & 169 & 246 & 225 & 174 \\
\hline Tensile strength $\sigma_{\mathrm{u}}(\mathrm{MPa})$ & 291 & 264 & 153 & 321 & 238 & 171 & 309 & 264 & 177 \\
\hline \multirow[t]{2}{*}{ Elongation \% } & 0.3 & 1.1 & 1.4 & 0.3 & 1.0 & 1.3 & 0.3 & 0.7 & 1.0 \\
\hline & \multicolumn{9}{|c|}{ Stirring rotational speed $=710 \mathrm{RPM}$} \\
\hline Travel speed (mm/min) & \multicolumn{3}{|c|}{16} & \multicolumn{3}{|c|}{20} & \multicolumn{3}{|c|}{25} \\
\hline Distance between two passes (mm) & 1 & 2 & 3 & 1 & 2 & 3 & 1 & 2 & 3 \\
\hline Yield strength $\sigma_{\mathrm{y}}(\mathrm{MPa})$ & 216 & 208 & 154 & 231 & 229 & 165 & 236 & 161 & 130 \\
\hline Tensile strength $\sigma_{\mathrm{u}}(\mathrm{MPa})$ & 289 & 252 & 155 & 279 & 288 & 167 & 290 & 188 & 132 \\
\hline \multirow[t]{2}{*}{ Elongation $\%$} & 0.1 & 1.0 & 1.2 & 0.2 & 0.9 & 1.0 & 0.3 & 0.1 & 0.7 \\
\hline & \multicolumn{9}{|c|}{ Stirring rotational speed $=900 \mathrm{RPM}$} \\
\hline Travel speed (mm/min) & \multicolumn{3}{|c|}{16} & \multicolumn{3}{|c|}{20} & \multicolumn{3}{|c|}{25} \\
\hline Distance between two passes (mm) & 1 & 2 & 3 & 1 & 2 & 3 & 1 & 2 & 3 \\
\hline Yield strength $\sigma_{\mathrm{y}}(\mathrm{MPa})$ & 235 & 235 & 149 & 248 & 224 & 151 & 264 & 227 & 145 \\
\hline Tensile strength $\sigma_{\mathrm{u}}(\mathrm{MPa})$ & 309 & 237 & 149 & 302 & 227 & 151 & 292 & 257 & 145 \\
\hline Elongation \% & 0.1 & 0.2 & 1.0 & 0.1 & 0.6 & 0.7 & 0.1 & 0.5 & 0.5 \\
\hline
\end{tabular}

